\title{
Cartazes de filmes: um exercício de letramento visual
}

\author{
Célia Elisa Alves de Magalhães \\ PUC - Rio
}

\section{Resumo}

Este artigo considera o conceito de letramento visual no domínio pedagógico e sugere sua aplicação no contexto de ensino-aprendizagem da língua materna, baseando-se nos pressupostos da Gramática Visual (Kress \& van Leeuwen, 2006) para a leitura de imagens em cartazes de filmes.

Palavras-Chave: gramática visual; letramento visual; cartazes.

\begin{abstract}
This article discusses the concept of visual literacy in the area of pedagogy and suggests its application in the context of learning-teaching in the mother tongue. The discussion is based on the theory of Visual Grammar (Kress \& van Leeuwen, 2006) for the reading of images in film posters.

Key-words: visual grammar; visual literacy; film posters.
\end{abstract}

\section{INTRODUÇÃO}

No Brasil, desde a década de 80, o termo letramento figura no meio acadêmico, tendo chegado às escolas como forma de diretrizes curriculares e pedagógicas, com a preocupação de vê-lo concretizar-se nas práticas de alfabetização em sala de aula. Nesse sentido, Rojo (2009, p. 98) aponta para o fato de que diferentemente do termo alfabetismo, que tem um foco individual e uma perspectiva psicológica; o termo letramento busca recobrir os usos e práticas sociais de linguagem que envolvem a escrita, englobando contextos sociais diversos numa perspectiva sociológica, antropológica e sociocultural. Ainda nesse contexto, Dionísio (2005, p. 131) ressalta a ideia de que o termo "letramento como habilidade de ler e escrever não abrange todos os diferentes tipos de representação do conhecimento existente em nossa sociedade” e argumenta que uma pessoa letrada deve ser "capaz de atribuir sentido a mensagens oriundas de múltiplas fontes de linguagem, bem como ser capaz de produzir mensagens, incorporando múltiplas fontes de linguagem”. De fato, diversos autores (Kleiman,1995; Kern, 2009; 
Marcuschi, 2001; Soares, 2001; Street, 1984, 2000) não só propuseram diferentes definições para o termo letramento, como também discutiram a aplicação dessa concepção teórica no domínio pedagógico, principalmente no que diz respeito à área de ensino-aprendizagem de língua materna.

Em termos escolares, Unsworth (2001, p. 8) defende que o letramento deve ser revisto como uma questão de multiletramento, pois o aluno precisa entender que há três tipos de linguagens, isto é, a verbal, a visual e a digital, sendo estas linguagens independentes e interativas na criação de significados. Certamente, um conceito mais abrangente de letramento pode fundamentar e transformar nossa prática pedagógica em ações que respondam às necessidades de nossos alunos no que concerne ao aprendizado, usos e práticas sociais da língua. No entanto, para isso, o enfoque da pesquisa em língua materna precisa ir além dos muros da escola, para a sociedade, onde as pessoas têm que desenvolver e aplicar os conhecimentos adquiridos na instituição escolar. Afinal, o conhecimento do código e da norma linguística não é suficiente para garantir a participação autônoma e crítica dos indivíduos em situações de comunicação. É preciso saber usar a língua em contextos reais e para fins específicos de comunicação.

Na sociedade pós-moderna, a comunicação envolve uma diversidade de modos de representação denominados recursos semióticos; isto é, a linguagem, as imagens, a música, os sons, e outros. Os recursos semióticos se combinam para produzirem significados que representam valores e ideologias. Dionísio (2005, p.160) indica que nossa sociedade está “cada vez mais visual”. Neiva (2002) argumenta que a imagem possui a faculdade de apontar para as coisas e, por ter essa propriedade de referência em comum com a língua, pode ser lida, embora os elementos da leitura visual e da linguística sejam diferentes. Entretanto, sabemos que, embora as imagens sejam utilizadas na sala de aula, esse uso é aleatório e secundário; ou seja, a imagem é apenas um apêndice ilustrativo do texto escrito. A fim de promover a real compreensão dos significados das imagens, é necessário que a escola promova o letramento visual, proporcionando, por exemplo, o conhecimento da "gramática visual” (Kress e Van Leeuwen, [1996] 2006).

Considerando o fato de que a imagem e a palavra mantêm uma relação cada vez mais próxima e integrada (Dionísio, 2005, p. 159), e a resultante importância do estímulo à prática do letramento visual nas escolas, o presente estudo tem como objetivo realizar 
leituras e interpretações de imagens veiculadas em cartazes de obras cinematográficas à luz da Gramática do Design Visual de Kress e van Leeuwen ([1996] 2006), relacionandose essa leitura à construção de significados sobre os filmes em questão.

Embora diferentes autores tenham desenvolvido estudos utilizando os postulados da Gramática do Design Visual de Kress e van Leeuwen ([1996 ]2006) voltados para questões pedagógicas (Nascimento, R.; Bezerra, F.A.S.; Heberle, E. M., 2011; Novellino, M. O., 2007; Silva, G. G., 2010; Teixeira, C. H. E. T., 2008a), a relevância da pesquisa consiste em sua contribuição para a sugestão de um exemplo de prática pedagógica aliada à utilização de uma "gramática visual" que possa oferecer uma sistematização para o que nossos alunos já fazem aleatória e inadvertidamente fora da sala de aula. O desenvolvimento de estratégias e atividades de letramento visual serve não apenas como alternativa ao tradicional ensino da leitura por meio de textos lineares em sala de aula, mas também como ponte para a promoção de uma reflexão sobre os textos imagéticos que permeiam nossa sociedade.

A base teórica para este trabalho busca referencial na gramática sistêmicofuncional de Halliday (1994), fazendo uma analogia entre as três funções da linguagem (ideacional/interpessoal/textual) estabelecidas por esse autor e a gramática visual, proposta por Kress e Van Leeuwen ([1996] 2006).

A seguir, são vistos alguns conceitos sobre o gênero cartaz de cinema e os pressupostos teóricos que fornecem os fundamentos para a análise dos dados gerados neste estudo, ou seja, a Gramática do Design Visual de Kress e van Leeuwen ([1996] 2006).

\section{CARTAZES DE FILMES}

As estruturas visuais, como materialização visual, podem ser fixas em diversos ambientes como paredes ou livros sejam eles virtuais ou não. Essas imagens apresentam diferentes propósitos, podendo estar veiculadas à informação, ao entretenimento, ou à publicidade. Uma forma comum de estrutura visual com o objetivo de divulgar visualmente uma informação é o cartaz, cuja concepção atual desenvolveu-se a partir do advento da litografia em 1860, quando começaram a ser produzidos por artistas de Paris e Londres para a divulgação de peças teatrais (Weill, 2004). 
Segundo Moles (1978, p. 20 apud Macedo, 2008, p.25), o cartaz “... nos países capitalistas, é um mecanismo publicitário ligado a motivações socioeconômicas, é um dos elementos outrora auxiliadores e doravante motores da sociedade de consumo; por outro lado é uma das formas modernas de arte na cidade”. Moretto (2008 apud Macedo, 2008, p. 25), afirma que as áreas culturais que mais demandam a produção de cartazes são as seguintes: o cinema, o teatro, as artes plásticas, a música, o circo e a política. É possível observar que atualmente há uma grande veiculação de cartazes de filmes tanto em espaços públicos como cinemas quanto em ambientes virtuais. Frequentemente, os fãs esperam ansiosamente pela divulgação desses cartazes que às vezes chegam à internet de forma incompleta, servindo como um teaser ${ }^{1} \mathrm{O}$ cartaz antecede e antecipa o filme. Ele proporciona um primeiro contato do espectador com o filme, criando um elo entre o conteúdo da trama e o que o espectador deseja ver.

Normalmente, o cartaz de filme apresenta determinadas características como título do filme, créditos principais, fotografia de cena do próprio filme ou uma imagem que faça referência à trama em questão ou mensagem veiculada. Isto é, há um modo próprio de composição nos cartazes de filmes, que por meio de recursos verbais e visuais, veicula objetivos particulares de uma situação de comunicação (Teixeira, 2008b, p.9). Uma das formas de leitura visual desses cartazes pode dar-se através da utilização dos pressupostos teóricos da Gramática do Design Visual (GDV) de Kress e van Leeuwen ([1996] 2006).

Vejamos, a seguir, os pressupostos teóricos que embasam essa gramática visual de Kress e van Leeuwen ([1996] 2006).

\section{A GRAMÁTICA VISUAL DE KRESS \& VAN LEEUWEN}

De acordo com Kress e van Leeuwen (1996, p.41-44), para que a imagem tenha a capacidade de significar, ela tem que servir a propósitos de comunicação e propósitos representacionais. Com base nessa premissa, os autores (op. cit, 1996) propõem uma

\footnotetext{
${ }^{1}$ Ferramenta publicitária de alto poder de persuasão que indica algo a ser anunciado sem revelar o produto, ou seja, o anunciante (Viana, 2010, p. 201, p. 34 apud Aita, 2011, p. 42). Recentemente, por exemplo, um dos cartazes de divulgação do filme Amanhecer, o quarto filme da saga Crepúsculo, foi lançado somente com o cenário que representava o amanhecer de um novo dia, ou seja, sem os personagens principais que viriam a integrar o referido cartaz em um outro momento, mais próximo da estréia do filme (Informação em http://crepusculo-amanhecer.filmetrailer.com. Acesso em 15 de novembro de 2011).
} 
gramática visual que apresente parâmetros para a observação de elementos que compõem imagens. Nesse sentido, esses elementos passam a ser considerados sintagmas visuais. Para isso, eles adotam a teoria das metafunções da linguística sistêmico-funcional de Halliday (1994).

Haliday (1994) argumenta que os elementos linguísticos podem ser explicados com referência a sua função, e categoriza as orações de três maneiras diferentes: ideacional, interpessoal e textual. A função ideacional especifica o papel dos elementos da oração na qual o significado está baseado na relação com os objetos e suas relações com o mundo. A função interpessoal está ligada às funções da fala e projeta as relações sociais entre o produtor, o receptor e o objeto representado. A função textual relaciona-se à capacidade dos sistemas semióticos formarem os textos e a mensagem em si. Consequentemente, diferentes arranjos composicionais resultam em diferentes significados textuais.

A partir do pressuposto de que o código da linguagem verbal e o código da linguagem visual possuem meios próprios para a sua realização bem como semelhanças nas suas relações semânticas, Kress e van Leeuwen ([1996] 2006) demonstram que a imagem é capaz de representar experiências e ações do mundo real (função ideacional); de representar relações entre o produtor da imagem, a imagem e o seu observador (função interpessoal); e de formar textos significativos (função textual).

\section{Classificações da gramática visual (Kress \& van Leeuwen)}

Considerando as relações linguísticas e visuais que podem ocorrer, Kress e van Leeuwen (1996) propõem a seguinte estrutura para a gramática visual com base na gramática sistêmico-funcional de Halliday (1994): A metafuncão ideacional relaciona-se à estrutura narrativa e a estrutura conceitual, sendo o termo participante empregado no lugar da palavra objeto; a metafunção interpessoal refere-se às representações e suas interações (ao contato, distância social, atitude e modalidade) e a metafunção textual diz respeito ao significado da composição, isto é, ao valor informativo, à saliencia e ao enquadramento, posicionando os elementos e provendo coerência. A seguir, são vistos, resumidamente, os conceitos e subdivisões de cada uma dessas estruturas segundo seus autores (Kress e van Leeuwen, [1996] 2006). 


\section{A estrutura narrativa}

A estrutura narrativa de Kress e van Leeuwen ([1996] 2006) analisa a representação das interações entre os participantes envolvidos em uma imagem através dos seguintes processos: ação transacional e não-transacional, reação transacional e nãotransacional, processo mental e verbal.

A representação da estrutura narrativa é feita através de vetores formados por elementos que podem ser braços ou pernas, por exemplo, e que partem dos participantes, chamados de atores da imagem. Quando há somente um participante, ele será o próprio ator e a ação será denominada não-transacional, pois não ocorre o direcionamento a alguém ou algo. Na linguagem verbal, os processos não-transacionais podem ser comparados aos verbos intransitivos. Quando há dois participantes, um é o ator e o outro é o alvo (goal) para quem a ação é direcionada. Na linguagem verbal, esse processo seria realizado por meio de verbos de ação.

Além dos processos narrativos que descrevem ações, existem os que descrevem reações. Neste caso, os processos são formados por vetores que partem dos olhos dos participantes retratados na imagem. No processo reacional transacional, existe um participante, chamado reagente (reactor) que olha para um outro participante, ou seja, o fenômeno (phenomena). Quando o participante olha para algo que parece estar fora da imagem, esse processo é caracterizado como um processo de reação não-transacional.

Finalmente, os processos mentais e verbais são aqueles ilustrados, por exemplo, em histórias em quadrinhos, onde a fala e o pensamento são representados através de textos colocados em balões com vetores que ligam esses textos aos personagens.

\section{A estrutura conceitual}

A estrutura conceitual descreve o participante representado em termos de classe, organização ou significado (Kress e van Leeuwen, 1996, p.79) através de três processos: classificatório, analítico e simbólico.

O processo classificatório mostra participantes que se apresentam como um grupo devido a uma característica comum. De acordo com a gramática visual de Kress e van Leeuwen ([1996] 2006), esse tipo de imagem é produzido visando à representação de 
uma taxonomia; consequentemente, normalmente a imagem não é natural. O processo analítico, que também tem essa característica de não-naturalidade, relaciona os participantes da imagem em uma estrutura de "parte-todo”, (Kress e van Leeuwen,1996 p.89), citando um portador (carrier), que é representado como o todo, e seus atributos possessivos, que representam suas partes. O processo simbólico se utiliza de procedimentos generalizáveis para manter uma relação de convenção com o que está representando.

\section{Estruturas de interação}

As estruturas de interação de Kress e van Leeuwen ([1996] 2006) dizem respeito às relações entre os participantes representados ou retratados na imagem e os participantes interativos, ou seja, os produtores e os espectadores da imagem. A partir desses participantes podem surgir interações caracterizadas por diferentes aspectos: por contato, distância social, atitude e modalidade.

A interação por contato ocorre quando um vetor traçado conecta os olhares do participante representado e do participante interativo (observador da imagem). Nesse caso, o olhar é de demanda. Por outro lado, se não houver conexão entre os olhares do participante representado e o do espectador, o olhar é denominado olhar de oferta. Outros vetores podem ser formados, por exemplo, um gesto por parte do participante representado, o qual solicita alguma coisa ao observador da imagem.

Em relação ao aspecto distância social, Kress e van Leeuwen ([1996] 2006) sugerem que distâncias curtas entre os participantes representados e os interativos (distância pessoal, distância íntima) estabelecem uma relação mais próxima; enquanto que as distâncias maiores (distância social) significam que os participantes são pessoas estranhas, que não tiveram um contato mais íntimo. O que determina a distância social entre os participantes é o tipo de corte utilizado na imagem. Por exemplo, a imagem do corpo inteiro do participante retratado confere um caráter de impessoalidade, enquanto que a imagem do rosto do participante representado vista com detalhes (corte em close) confere um caráter de proximidade/intimidade.

A perspectiva em que uma imagem é retratada implica em relações interativas relacionadas à atitude, que pode ser classificada como de subjetividade e de objetividade 
(Kress e van Leeuwen, 1996, p.149). Quando a imagem é objetiva, sua perspectiva é central e o ponto de vista é construído pelo produtor. Quando a imagem é subjetiva, o ponto de vista é selecionado pelo observador. A questão do ângulo também determina a representação das imagens subjetivas sob duas formas: uma retratando envolvimento por parte do participante representado, sendo definida pelo ângulo frontal do corpo deste participante, e a outra sugerindo distanciamento por parte deste participante, sendo definida pela posição do corpo do participante representado em ângulo oblíquo. As imagens subjetivas também podem sugerir relações de poder entre os participantes retratados e os interativos. Quando o participante retratado é visto de um ângulo superior, o participante interativo se encontra em posição de poder. Quando o participante retratado olha diretamente no olho do participante interativo existe uma relação de igualdade de poder. Finalmente, quando o participante retratado é visto de um ângulo baixo, o participante interativo encontra-se em situação de inferioridade.

Os estudos de Kress e van Leeuwen (2006, p. 160-163) sugerem que a modalidade infere o valor de verdade, isto é, o nível de realidade da imagem variando do “mais real” ao "menos real”. Os aspectos da modalidade da imagem são classificados segundo as seguintes características: saturação de cor (total saturação até o preto e branco); diferenciação de cor (máxima diversidade de cores até a monocromia); modulação de cor (utilização máxima de tons de uma determinada cor até a utilização da cor pura); contextualização (ausência de cenário até o cenário cheio de detalhes); representação (máxima abstração até o máximo de detalhes); profundidade (ausência de profundidade até total profundidade); iluminação (ausência de iluminação até excesso de iluminação); e brilho (nível máximo de brilho até os tons cinzentos).

\section{Estruturas de Organização: A composição da imagem}

Na obra Gramática do Design Visual, Kress e van Leeuwen ([1996] 2006), apresentam três princípios relativos à composição que ocorrem dentro de uma mesma imagem ou em imagens de páginas de revista, por exemplo: valor informativo, saliência e enquadramento.

O primeiro princípio da composição, o valor informativo, está relacionado aos lugares específicos em que os elementos aparecem na imagem: parte superior e parte 
inferior, lado esquerdo e lado direito, centro e margem. O valor informativo da parte superior de uma imagem é a informação ideal e gera um apelo emotivo, podendo expressar uma promessa. Já a parte inferior é vista como a informação real, concreta e prática da informação. Às vezes, a imagem também apresenta o que Kress e van Leeuwen (1996, p. 199) denominaram de tríptico, isto é, elementos centrais que conectam o ideal ao real. O valor informativo na posição esquerda /direita da unidade semiótica é a informação que parte do dado para o novo. O lado esquerdo, o dado, seria a informação que já é de conhecimento do participante interativo; enquanto o lado direito, o novo, apresenta a informação a qual o participante interativo deve prestar atenção. O valor informativo centro/margem determina que o elemento posicionado no centro de um texto imagético seja considerado o núcleo da informação, a qual os demais elementos serão subservientes, encontrando-se na margem e, por isso, denominados elementos marginais.

De acordo com Kress e van Leeuwen ([1996] 2006), o segundo princípio da composição, a saliência, atribui ao texto uma hierarquia de importância entre os elementos. Esses elementos são feitos salientes para chamar a atenção do observador em diferentes graus. Os recursos de saliência utilizados são os seguintes: tamanho dos elementos, cores fortes, contraste de cores, tonalidades, efeitos de sombra, sobreposição, perspectiva da posição dos elementos colocados na composição, entre outros.

O terceiro e último princípio, o enquadramento, relaciona-se à presença ou ausência de planos de estruturação que desconecta ou conecta elementos da imagem, ou do texto multimodal, significando que eles pertencem ou não ao mesmo sentido. Este efeito pode ser realizado por diferentes formas, através de elementos que criam linhas divisórias ou linhas de estruturação reais. As linhas podem ser contínuas ou descontínuas apresentando uma gradação de cores e até espaços em branco.

A partir dos pressupostos teóricos da GDV de Kress e van Leeuwen ([1996] 2006) são vistas na sequência a metodologia de pesquisa e a análise dos dados gerados.

\section{METODOLOGIA DE PESQUISA}

A metodologia de pesquisa adotada insere-se na tradição de pesquisas qualitativas (Denzin e Lincoln, 2006), sendo fundamentada no modelo de análise da Gramática do Design Visual proposta por Kress \& van Leeuwen ([1996] 2006) cujo trabalho apoia-se 
na teoria das metafunções da linguística sistêmico-funcional de Halliday (1994). É pertinente ressaltar que neste estudo não serão analisados textos escritos nem as fontes utilizadas na elaboração dos mesmos, estando a presente análise restrita a leitura das imagens.

Na geração de dados, foram utilizados quatro cartazes que veiculam informações sobre os seguintes filmes: A Pele que Habito, A Chave de Sara, Jardins das Folhas Sagradas e Amanhecer-parte 1. Tanto os cartazes quanto as informações sobre os filmes foram retirados de sites da internet, acessados em 15 de novembro de 2011. Os filmes foram escolhidos aleatoriamente dentre os filmes que ficaram em exibição nas salas de cinema no mês de novembro de 2011.

O filme A Pele que Habito retrata a trama de um cirurgião plástico que, após a morte de sua esposa num acidente, concentra suas energias e conhecimento na criação de uma pele com a qual ela poderia ter sobrevivido. Porém, para chegar a um resultado perfeito, seria necessário utilizar uma cobaia humana (http://gds-www t0.novosnegociosrbs.com.br/cinema). A Chave de Sarah conta a história de uma jornalista que vê a sua vida envolvida com a de uma garota chamada Sarah: uma menina cuja família foi destruída por nazistas na maior perseguição de judeus na França (http://cinema10.com.br). O filme Jardim das Folhas Sagradas é uma ficção construída a partir de um bancário bem sucedido que recebe a incumbência de montar um terreiro de candomblé no espaço urbano, onde enfrentará a especulação imobiliária, o preconceito racial e a intolerância religiosa (http://cinema10.com.br). Em Amanhecer - parte 1, o quarto filme da saga Crepúsculo, Bella Swan e o vampiro Edward Cullen se casam e passam sua lua-de-mel em uma ilha do Atlântico, perto do Rio de Janeiro, mas Bella descobre estar grávida, e então o casal volta repentinamente para casa.

A seguir, os cartazes dos fimes são analisados segundo as premissas da GDV.

\section{ANÁLISE DE CARTAZES DE OBRAS CINEMATOGRÁFICAS}

Observa-se que o gênero cartaz de filme apresenta aspectos estruturais que relacionam palavras e imagens, atuando semanticamente de forma a familiarizar o público com a trama do filme em questão. Os aspectos estruturais relativos ao texto verbal dos cartazes de filmes são os títulos, os nomes dos atores e diretores, o ano de 
lançamento e frases de efeito que sintetizam a história do filme ou dizem respeito a uma ideologia presente nele. Por outro lado, o texto imagético nesses cartazes é composto por imagens, geralmente em cores, que podem representar, por exemplo, uma cena em particular, ou uma seleção de cenas do filme, ou simplesmente os rostos/corpos dos atores em diferentes posições, ângulos ou perspectivas. Os cartazes dos filmes a seguir (figuras 1 - 4) exemplificam esse gênero.

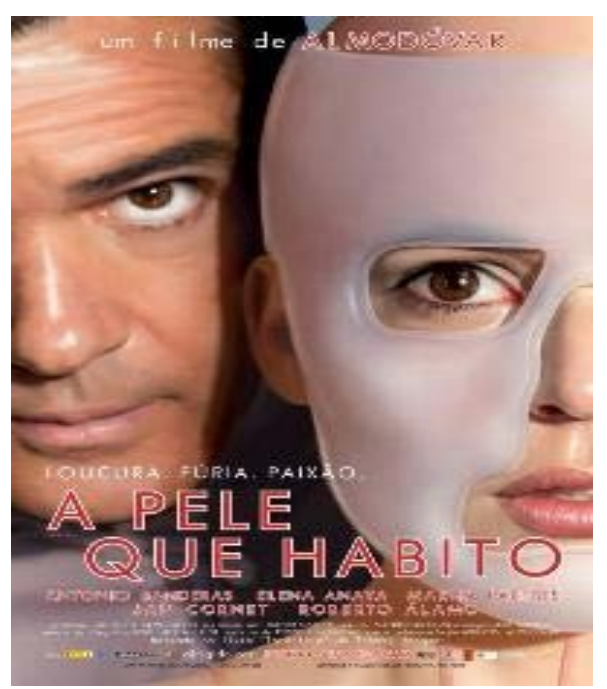

Figura 1: Filme - A Pele que Habito Retirado de www.adorocinema.com Acesso em 15/11/2011.

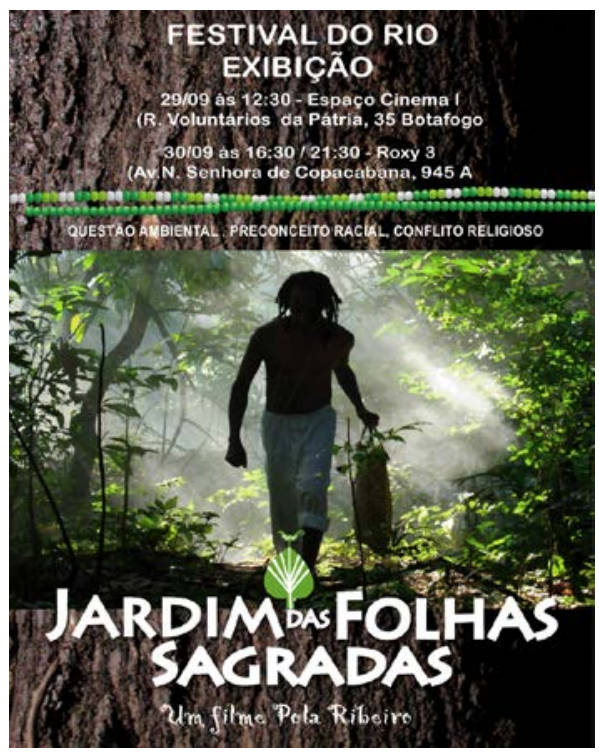

Figura 3: Filme - Jardim das Folhas Sagradas Retirado de www.adorocinema.com Acesso em 15/11/2011.

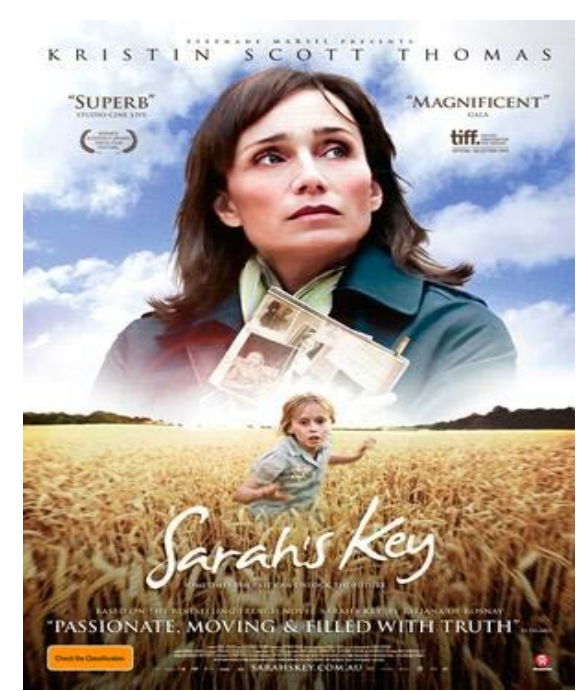

Figura 2: Filme - A Chave de Sarah Retirado de www.adorocinema.com Acesso em 15/11/2011.

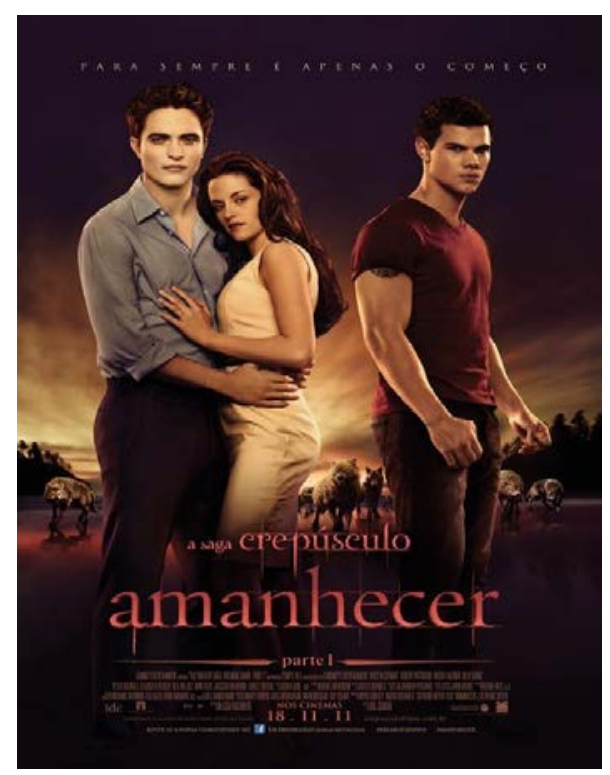

Figura 4: Filme - Amanhecer Retirado de http://pipocamoderna.com.br Acesso em 15/11/2011. 


\section{A Pele que Habito}

Segundo Nascimento et al (p. 537, 2011), “diferentemente das representações narrativas, nas quais os participantes são captados durante o curso de uma ação ou acontecimento, nas representações conceituais, o foco são os atributos e as identidades dos participantes.” No cartaz de filme A Pele que Habito (figura 1), não há presença de elementos que caracterizam a estrutura narrativa. Entretanto, é possível identificar a estrutura conceitual realizada através do processo analítico, representado por elementos na imagem que se apresentam em uma relação de parte/todo. Tal representação encontrase na ausência de plano de fundo, o que põe foco nos atributos dos participantes como a máscara sobre o rosto da mulher à esquerda do texto imagético. A mulher é portadora de uma informação relacionada à máscara.

A estrutura interacional, que se refere à interação entre o participante retratado na imagem e o observador, pode ter tal relação fortalecida ou enfraquecida através do contato, ou seja, do olhar do participante representado na imagem para seu espectador. No cartaz do filme A Pele que Habito os vetores traçados pelos olhares dos participantes da imagem com o do espectador compõem um olhar de demanda, pois os participantes representados, o homem e a mulher, estão olhando diretamente para os olhos do espectador, estabelecendo, assim, um contato de certa forma imaginário com o mesmo. A distância social é outro aspecto que determina o tipo de relação estabelecida entre o participante representado e o espectador. O enquadramento de uma figura através da escolha entre diferentes planos sugere diferentes relações entre os participantes envolvidos. O cartaz do referido filme apresenta a escolha de um primeiro plano, apresentando assim uma distância curta, entre o participante representado e o espectador, o que estabelece uma relação íntima e pessoal. A perspectiva em que uma imagem é retratada também implica relações interativas referentes à atitude. Nesse sentido, percebemos que o homem está olhando frontalmente para o espectador, porém com leve inclinação do olhar para cima, o que pode sugerir que o espectador está em uma posição superior de poder, ou de censura, em relação ao homem. A mulher, no entanto, encontrase retratada na posição frontal olhando diretamente para o observador, em uma espécie de apelo. A figura da mulher também encontra-se em destaque na imagem devido aos seguintes aspectos da modalidade: a ausência de cenário; a profundidade criada pela 
posição do rosto do homem colocado ligeiramente atrás do rosto da mulher; a iluminação, que cria uma sombra entre o rosto da mulher e o do homem; o brilho na pele do rosto do homem; e a cor branco acinzentada em tom opaco na máscara da mulher.

Os significados composicionais, isto é, a estrutura de organização, referem-se à distribuição dos elementos dentro do espaço visual, bem como ao modo em que os elementos representacionais e interacionais são integrados num todo significativo. O lado direito da imagem, por exemplo, representa o lado da informação chave, a informação nova, o que desperta maior atenção do observador, ao passo que o lado esquerdo representa a informação dada. Na figura 1, o homem está posicionado do lado esquerdo da imagem; enquanto que a mulher, cujo rosto está coberto com uma espécie de máscara cirúrgica de cor clara, apresenta-se do lado direito, o lado da informação chave. Desta forma, o leitor da imagem pode inferir que a informação dada relaciona-se ao homem, que pode ser um cirurgião, e que a informação nova refere-se à mulher e a sua máscara cirúrgica. Há também uma sombra formada pelo ângulo da cabeça da mulher com a cabeça do homem, criando uma espécie de linha divisória. Além disso, é possível ver somente metade de cada um dos rostos, ou seja, a metade esquerda do rosto do homem e a metade direita do rosto da mulher, como se essas metades (ou os próprios participantes representados) se completassem, ou como se a informação dada complementasse a nova. A sobreposição da máscara quase monocrômica no rosto mulher confere saliência à imagem, ocasionando a ilusão de um efeito tridimensional e fornecendo relevância a informação nova relacionada à mulher.

A partir das observações feitas com base na Gramática Visual de Kress e van Leeuwen ([1996] 2006), conclui-se que a leitura do texto imagético no cartaz do filme $A$ Pele que Habito pode ajudar o observador (leitor) a construir alguns dos elementos que compõem a trama do filme: um cirurgião plástico que concentra suas energias e conhecimento na criação de uma pele humana.

\section{A Chave de Sarah}

O cartaz do filme A Chave de Sarah apresenta as figuras de uma menina e de uma mulher. A menina está correndo de braços abertos no meio de uma plantação, aparentemente na direção do observador. Um dos braços da menina está direcionado para 
trás e o outro para frente na direção do espectador. Os braços atuam como vetores de uma ação não-transacional, pois somente um ator está envolvido, compondo a estrutura narrativa da imagem e representando a ação de correr.

A partir da análise da estrutura conceitual do texto imagético, é possível inferir que a mulher retratada porta informações sobre algo ou alguém. Tal conclusão origina-se do fato de que a mulher parece estar segurando uma revista, ou um livro.

Através das estruturas de interação, observa-se que, quanto ao elemento contato, a mulher representada na imagem apresenta uma expressão pensativa e olhar de oferta. A imagem do tipo oferta oferece os atores da imagem ao observador como itens de informação, como se eles fossem exemplares de uma exposição (Kress e van Leeuwen, 1996, p. 124). A menina apresenta um olhar de demanda, como se fizesse um apelo ao observador. No que diz respeito à distância, aspecto que reflete o nível de intimidade e é representada pelo posicionamento (próximo ou distante) do participante retratado, a mulher encontra-se em plano médio (distância social) e a menina em plano aberto (distanciamento impessoal). Quanto à atitude, item que informa o nível de envolvimento com o leitor e é conferida por intermédio do ângulo frontal (maior envolvimento) ou oblíquo (menor envolvimento), a mulher está em ângulo frontal, apresentando maior envolvimento com o leitor; enquanto que a menina encontra-se em ângulo ligeiramente oblíquo, o que indica uma relação de separação, de distanciamento do espectador.

A distribuição dos elementos da estrutura de organização dentro do espaço visual pode-se dar através do valor informativo, isto é, da estrutura Ideal-Real, estabelecida pela organização dos itens colocados na seção superior e inferior da imagem (Kress e van Leeuwen, [1996] 2006). Em imagens verticalmente orientadas, os elementos constituintes da parte superior são chamados de ideais, ao passo que os elementos constituintes da parte inferior são chamados de reais. No cartaz do filme A Chave de Sarah, (Figura 2) observa-se uma linha divisória horizontal formada por uma espécie de vegetação no plano de fundo, e a figura de mulher que se encontra na parte superior da imagem, na zona do ideal.

O plano de fundo da parte superior, parte do ideal, onde se encontra a mulher, retrata o céu (ou firmamento). O céu representado atribui um elemento de saliência à composição visual devido às cores branca e azul que fornecem uma noção de 
profundidade à imagem. A própria imagem da mulher em tamanho desproporcional aos demais itens que compõem o texto imagético do cartaz também se apresenta como um elemento de saliência. Nesse sentido, a saliência confere à mulher uma maior importância. As roupas da mulher também apresentam tons de azul e verde, lembrando a cor do céu/firmamento, o que associa a sua imagem ao poder divino. Há ainda uma luz branca saindo da mulher na altura do centro da imagem que alude a essa mesma ideia relativa ao divino além de chamar a atenção do espectador para a figura da menina e da revista/livro que a mulher segura. As características relativas à saturação e à modulação de cor, à profundidade, à iluminação e ao brilho bem como a riqueza de detalhes no cenário constituem os aspectos que compõem a modalidade, elemento da estrutura de interação que infere o nível de realidade da imagem, classificando a mesma em um contínuo de "mais real" até o "menos real".

Na parte inferior, isto é, no lugar do concreto (real), encontra-se a menina com uma expressão assustada. O plano em que a menina está contém elementos de saliência organizacional como a cor dourada da plantação. A parte inferior e a parte superior da imagem criam desconexões e, ao mesmo tempo, conexões que compõem o enquadramento, outro elemento organizacional.

Novamente, nota-se que o texto imagético no cartaz do filme A Chave de Sarah dialoga com a história narrada na sinopse do filme: uma jornalista vê sua vida envolvida com a de uma menina cuja família foi destruída por nazistas.

\section{Jardim das Folhas Sagradas}

No cartaz do filme Jardim das Folhas Sagradas (Figura 3), as diferentes estruturas de composição da gramática visual - narrativa, conceitual, de interação e de organização - mesclam-se, fundindo-se em um texto imagético permeado por aspectos da modalidade, constituinte da estrutura interacional. A contextualização, ou seja, o cenário repleto de detalhes relativos às cores e formas dos diferentes itens retratados (a floresta, o tronco, o colar sobre o tronco, as folhas, o homem, a bolsa), a iluminação e o brilho advindos da luz que incide no centro da imagem, e os efeitos de profundidade criados por esses elementos auxiliam na composição imagética de simbolismos relacionados à religião e à natureza, temas que compõem o enredo do filme. No que tange à distância, o 
posicionamento do participante retratado por meio do plano aberto cria uma relação de menor intimidade com o leitor. Por outro lado, no que diz respeito à atitude, o ângulo frontal confere um maior envolvimento entre o participante representado e o espectador.

Conforme visto nas subseções anteriores, a estrutura de organização descreve a relação entre os elementos que compõem uma imagem visual e encontra-se estruturada através de três sistemas: o valor da informação, que corresponde ao posicionamento dos elementos numa dada imagem, organizada pelas estruturas Dado/Novo, Ideal/Real e Centro/Margem; a saliência, representada por aspectos como tamanho, contraste de cores e posição de elementos no plano de frente da imagem, criando assim uma "hierarquia de importância entre os elementos" (Kress e van Leeuwen, 1996, p. 212); e o enquadramento, estabelecido através da conexão e desconexão entre os elementos descritos.

No cartaz do filme Jardim das Folhas Sagradas constata-se que a natureza apresenta-se valorizada pela cor verde, elemento de saliência na imagem. Mas outros aspectos que destacam a natureza podem ser encontrados nesse texto imagético, como por exemplo, as extremidades superiores e inferiores do cartaz compostas pela figura de um tronco de árvore com um espaço (ou corte) no meio. Os lados superior e inferior direito da imagem apresentam tonalidade escura, dando um tom de mistério à situação representada. Na parte superior da imagem, há ainda uma espécie de linha divisória formada por colares de contas brancas e verdes - colares usados pelos seguidores dos rituais de Umbanda, o que também indica aspectos de religiosidade. As cores dos colares também são significativas: o branco da religião e o verde da natureza. Essas contas formam duas linhas que se cruzam, talvez em alusão a questões que estão interligadas: natureza e religião.

Através do corte na árvore é possível ver a figura de um homem. A floresta verde encontra-se ao redor do homem e há também uma luz, provavelmente a luz do sol, que incide do topo esquerdo da imagem iluminado mais fortemente o lado direito da mesma, criando efeitos de sombra e de profundidade. Do lado esquerdo, há galhos, troncos finos e folhas; do lado direito (o lado da informação chave) vê-se somente folhas, provavelmente, uma alusão ao nome do filme: Jardim das Folhas Sagradas. O homem, posicionado no centro da imagem, está vestindo uma calça branca, cor que remete-nos a 
aspectos de religiosidade, e carregando uma espécie de bolsa com folhas, que é segurada do lado direto da tela, fato que, segundo pressupostos da estrutura conceitual, o constrói como portador de uma informação nova. O corte central no tronco da árvore bem como os colares de contas na parte superior do corte formam o plano de estruturação que constituem o enquadramento da imagem. Como o homem parece estar dentro do tronco, é possível interpretar que a natureza e o homem com sua religiosidade estão interligados.

A estrutura narrativa também está presente no cartaz do filme em questão, sendo representada na figura do homem caminhando em direção ao observador da imagem. Os vetores formados pelos braços do homem compõem a ação de caminhar que identifica a representação narrativa.

Conclui-se que as imagens do cartaz do filme Jardim das Folhas Sagradas fornecem os elementos necessários (relacionados à natureza e religião) para a leitura do enredo do filme: um homem recebe a incumbência de montar um terreiro de candomblé no espaço urbano, onde enfrentará a especulação imobiliária, o preconceito racial e a intolerância religiosa.

\section{Amanhecer}

Segundo Kress e van Leeuwen ([1996] 2006), a estrutura narrativa relaciona os participantes em termos de desdobramento de ações, acontecimentos e processos de mudança dos quais eles tomam parte. Nesse sentido, a representação da estrutura narrativa é feita através de vetores formados por elementos que podem ser braços ou pernas. No cartaz do filme Amanhecer, quarto filme da saga Crepúsculo, há vetores traçados dos corpos dos participantes retratados do lado esquerdo da imagem, através dos braços deles. O rosto da mulher na imagem também atua como um vetor apontando para o rosto do homem. Devido a esses vetores, os participantes representados na interação constituem-se no ator e alvo de um mesmo processo na estrutura de interacão.

Além de se aproximarem ou se distanciarem, as imagens podem interagir com os leitores, "solicitando que o leitor faça algo" ou "oferecendo algo ao leitor" (Kress e van Leeuwen, [1996 ] 2006). Esse contato é feito através dos olhares de demanda ou oferta. Na imagem em questão, observa-se que os três participantes representados interagem com o observador através do alinhamento de seus olhares de demanda que buscam 
cumplicidade. Além disso, a distância curta entre os participantes representados na imagem e os participantes interativos (distância pessoal) estabelece uma relação mais próxima. Todavia, os corpos dos participantes retratados encontram-se em ângulo oblíquo, o que representa certa impessoalidade e distanciamento do espectador. O cenário com detalhes no plano de fundo, a iluminação e o brilho proveniente da saturação/modulação de cores como o preto, o vermelho e o branco criam efeitos de profundidade, de simbolismo e de mistério.

Quanto à estrutura de organização, nota-se que a parte superior da imagem e a inferior apresentam cores bem escuras, um aspecto de saliência que coloca em destaque a figura dos personagens no centro da imagem. O fato de não haver nenhuma imagem que represente uma informação ideal (parte superior) e outra real (parte inferior) pode significar que a informação idealizada e a realidade estão mescladas, ou seja, são uma só. As cores escuras na parte superior e inferior da imagem também atuam como linhas divisórias na composição do enquadramento da imagem. Outro elemento de saliência está relacionado à luminosidade saindo do plano de fundo da imagem em direção ao centro da mesma. Essa luz ilumina o casal, Bella e Edward. A luz representa o nascer do sol, o Amanhecer, título do filme. No plano de fundo, há também alguns lobos.

O fato de o personagem Jacob encontrar-se do lado direito da imagem está relacionado a uma informação nova, possivelmente a ser desvendada no filme. Outro fator coloca esse personagem em evidência: a cor vermelha de sua camisa. Segundo Dondis (1997, p.108), a cor está impregnada de informações, sendo por isso uma fonte de valor inestimável para os comunicadores visuais. A cor vermelha, frequentemente associada à paixão na cultura ocidental, poderia, por exemplo, levar o espectador a inferir que Jacob terá um (novo) envolvimento amoroso uma vez que ele se encontra sozinho do lado direito da imagem, lado da informação nova. Em contraste, Bella, a noiva do vampiro Edward, veste uma roupa de cor clara e luminosa, o que poderia representar a cor do seu vestido de noiva e a pureza de Bella, que (ainda) não foi transformada em vampira. Na saga de Crepúsculo, Jacob pertence à tribo Quileute, sendo também um 
lobisomem/transfigurador ${ }^{2}$. Se o espectador conhecer a história dessa saga, reconhecerá e associará esse conhecimento aos elementos na imagem. Caso contrário, o observador poderá inferir a existência de algum tipo de ligação entre os lobos presentes no cenário e o(s) participante(s) representado(s).

No cartaz do filme Amanhecer não são evidenciados elementos que formam a estrutura conceitual. No entanto, a trama sobre vampiros, homens-lobo e humanos revelase no texto imagético representado no cartaz do filme em questão através da leitura fundamentada pelas demais estruturas que compõem a gramática visual de Kress e van Leeuwen ([1996] 2006).

A seguir, encontram-se dois quadros resumo com os princípios da GDV e os elementos presentes na composição de cada um dos cartazes analisados

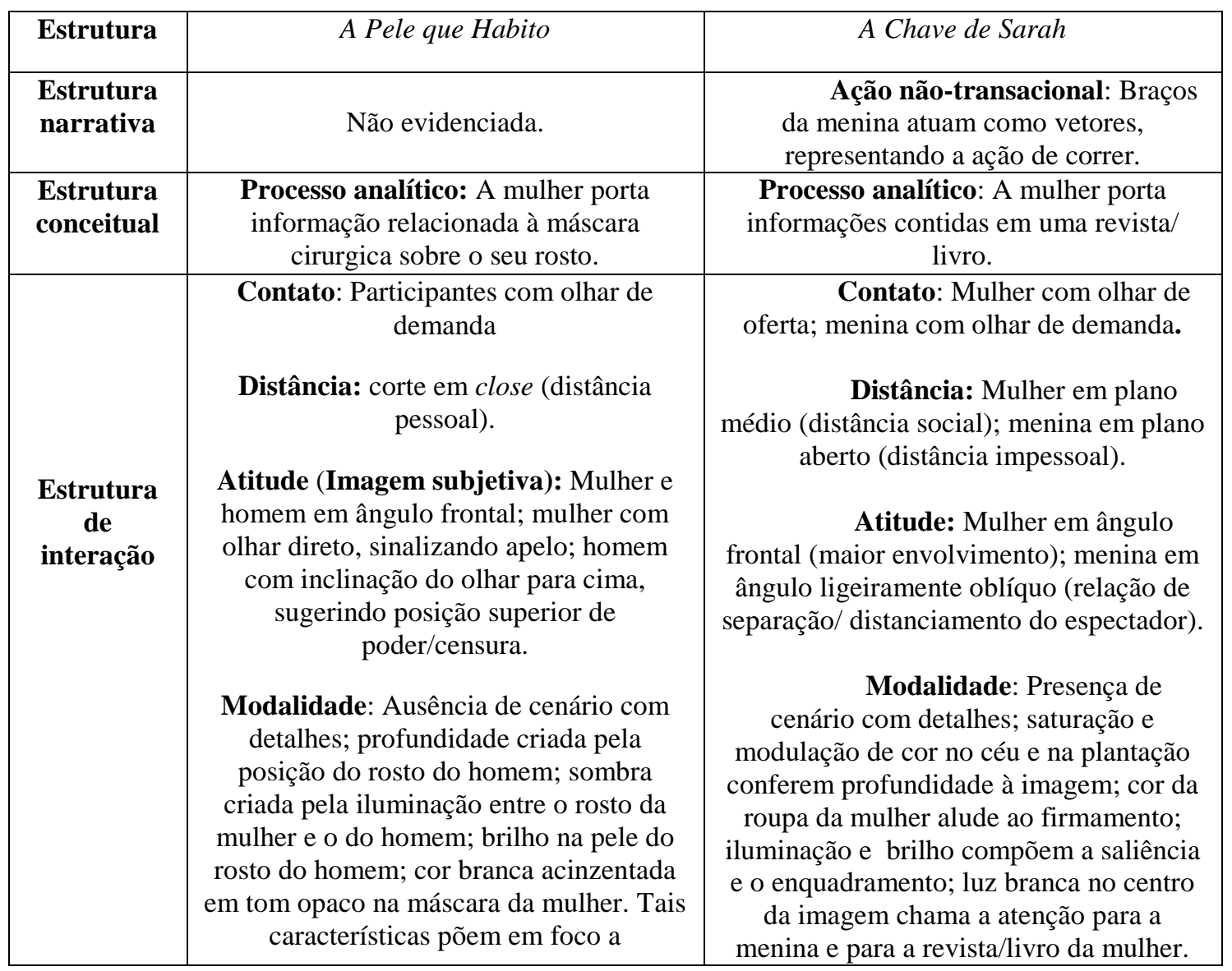

\footnotetext{
2 Jacob Black é o melhor amigo de Bella. A partir de Lua Nova (o segundo filme da saga Crepúsculo), ele passa a ter maior importância na história, dando grande apoio a Bella, depois da partida de Edward, e acaba se apaixonando por ela (Informação disponível em http://pt.wikipedia.org/wiki/Anexo:Lista_de_personagens_da_serie_Crepúsculo. Acesso em 24 de novembro de 2011).
} 


\begin{tabular}{|c|c|c|}
\hline & informação nova. & \\
\hline $\begin{array}{c}\text { Estrutura } \\
\text { de } \\
\text { organização }\end{array}$ & $\begin{array}{l}\text { Valor informativo: } \\
\text { Lado esquerdo: Informação dada, } \\
\text { relacionada ao homem. Lado direito: } \\
\text { Informação nova sobre a mulher/ } \\
\text { máscara. } \\
\text { Saliência: Sobreposição da máscara } \\
\text { quase monocrômica no rosto mulher } \\
\text { ocasiona efeito tridimensional, } \\
\text { fornecendo relevância à informação nova. } \\
\text { Enquadramento: Efeito criado por } \\
\text { sombra formada pelo ângulo da cabeça da } \\
\text { mulher com a cabeça do homem, constrói } \\
\text { linha divisória. A metade esquerda do } \\
\text { rosto do homem e a metade direita do } \\
\text { rosto da mulher complementam-se, como } \\
\text { se a informação dada complementasse a } \\
\text { nova. }\end{array}$ & $\begin{array}{c}\text { Valor informativo: } \\
\text { Parte superior (zona do Ideal): Imagem } \\
\text { do céu (firmamento) e da mulher. Parte } \\
\text { inferior (zona do Real): Imagem da } \\
\text { plantação e da menina. Centro da } \\
\text { imagem: Núcleo da informação onde } \\
\text { estão retratadas a mulher e a menina. } \\
\text { Saliência: Composição visual do } \\
\text { céu com cores branca e azul, e a cor } \\
\text { dourada da plantação fornecem noção de } \\
\text { profundidade; imagem da mulher adquire } \\
\text { maior importância devido ao seu tamanho } \\
\text { desproporcional. } \\
\text { Enquadramento: Parte inferior } \\
\text { e superior da imagem criam desconexões } \\
\text { e conexões que compõem a linha divisória } \\
\text { entre os planos. }\end{array}$ \\
\hline
\end{tabular}

Quadro 1: Princípios da GDV e elementos presentes na composição dos cartazes dos filmes $A$ Pele que Habito e A Chave de Sarah.

\begin{tabular}{|c|c|c|}
\hline Estrutura & Jardim das Folhas Sagradas & Amanhecer \\
\hline $\begin{array}{l}\text { Estrutura } \\
\text { narrativa }\end{array}$ & $\begin{array}{l}\text { Ação não-transacional: Braços e } \\
\text { pernas do homem atuam como vetores, } \\
\text { representando a ação de caminhar. }\end{array}$ & $\begin{array}{c}\text { Ações Transacional vetores partindo dos } \\
\text { braços e rostos do homem e da mulher que } \\
\text { se abraçam. }\end{array}$ \\
\hline $\begin{array}{l}\text { Estrutura } \\
\text { conceitual }\end{array}$ & $\begin{array}{c}\text { Processo analítico: O homem porta } \\
\text { informações referentes à bolsa que } \\
\text { carrega. }\end{array}$ & Não evidenciada. \\
\hline $\begin{array}{l}\text { Estrutura } \\
\text { de } \\
\text { interação }\end{array}$ & $\begin{array}{l}\text { Distância: Homem em plano } \\
\text { aberto retrata relação de menor intimidade } \\
\text { com o leitor (distância impessoal). } \\
\text { Atitude: Homem em ângulo } \\
\text { frontal indica maior envolvimento entre o } \\
\text { participante representado e o espectador. } \\
\text { Modalidade: Cenário com detalhes, } \\
\text { iluminação/brilho da luz no centro da } \\
\text { imagem, e efeitos de profundidade } \\
\text { criam simbolismos relacionados à } \\
\text { religião e à natureza. }\end{array}$ & $\begin{array}{l}\text { Contato: Participantes com olhar de } \\
\text { demanda. } \\
\text { Distância: Distância curta entre os } \\
\text { participantes representados e o especador } \\
\text { estabelece uma relação próxima. } \\
\text { Atitude: A posição dos corpos dos } \\
\text { participantes em ângulo oblíquo representa } \\
\text { impessoalidade e distanciamento do } \\
\text { espectador. } \\
\text { Modalidade: Cenário com detalhes, } \\
\text { iluminação/brilho proveniente da } \\
\text { saturação/modulação de cores (preto, } \\
\text { vermelho e branco) criam efeitos de } \\
\text { profundidade, simbolismo e mistério. }\end{array}$ \\
\hline
\end{tabular}




\begin{tabular}{|c|c|c|}
\hline $\begin{array}{l}\text { Estrutura } \\
\text { de } \\
\text { organização }\end{array}$ & $\begin{array}{l}\text { Valor informativo: } \\
\text { Parte superior: Colares usados } \\
\text { em rituais religiosos formam duas linhas } \\
\text { que se cruzam (alusão a questões } \\
\text { relacionadas à natureza e à religião). Parte } \\
\text { inferior: Tronco da árvore com nuances } \\
\text { de tonalidade escura confere mistério à } \\
\text { situação retratada. Lado esquerdo: } \\
\text { Galhos, troncos finos e folhas representam } \\
\text { a floresta. Lado direito: Somente folhas } \\
\text { como alusão ao nome do filme; bolsa com } \\
\text { folhas representa informação chave. } \\
\text { Centro: Corte na árvore mostra o homem } \\
\text { carregando uma bolsa com folhas e } \\
\text { vestindo uma calça branca, cor que remete } \\
\text { à religiosidade. } \\
\text { Saliência: Natureza valorizada } \\
\text { pela saturação/modulação da cor verde, } \\
\text { efeitos de sombra, profundidade criada } \\
\text { pela iluminação e brilho provenientes da } \\
\text { luz central. } \\
\text { Enquadramento: Efeito criado } \\
\text { pelo corte central no tronco da árvore e } \\
\text { pelos colares na parte superior do corte } \\
\text { indica que o homem dentro do tronco, a } \\
\text { sua religião e a natureza estão interligados. }\end{array}$ & $\begin{array}{l}\text { Valor informativo: } \\
\text { Parte superior e inferior da imagem } \\
\text { apresentam cores bem escuras, um aspecto } \\
\text { de saliência que põe em foco os } \\
\text { participantes no centro da imagem. Lado } \\
\text { direito: O personagem Jacob representa } \\
\text { uma informação nova a ser desvendada. } \\
\text { Lado esquerdo: A informação dada refere- } \\
\text { se ao relacionamento de Bella e Eduard. } \\
\text { Saliência: A cor escura na parte superior e } \\
\text { inferior da imagem, a luminosidade saindo } \\
\text { do plano de fundo e simbolizando o } \\
\text { Amanhecer, a cor branca do vestido da } \\
\text { mulher e a cor vermelha da camisa do } \\
\text { homem à direita colocam os participantes } \\
\text { retratados em destaque. } \\
\text { Enquadramento: As cores escuras na } \\
\text { parte superior e inferior do cartaz formam } \\
\text { linhas compondo o enquadramento da } \\
\text { imagem. }\end{array}$ \\
\hline
\end{tabular}

Quadro 2: Princípios da GDV e elementos presentes na composição dos cartazes dos filmes Jardim das Folhas Sagradas e Amanhecer.

\section{CONSIDERAÇÕES FINAIS}

O domínio de uma língua é resultado de práticas significativas e contextualizadas. Contudo, de acordo com Romanowski, Martins e Junqueira (2004, p. 24), a aprendizagem será mais significativa, viva e enriquecedora se os alunos fizerem pontes entre o que aprendem intelectualmente e as situações reais, experimentais, e profissionais ligadas aos seus estudos. Por isso, a escola deve imitar em suas práticas pedagógicas as atividades linguísticas do cotidiano, e ter a experiência de vida como ponto de partida para promover a aprendizagem autônoma e produtiva. Nesse sentido, as ações pedagógicas que envolvem a prática do letramento visual possibilitam ao aprendiz associar os conhecimentos construídos na escola a aqueles construídos no mundo real, permitindo que a aprendizagem funcione como um jogo de descobertas onde perceber 
cores, formas, linhas, ângulos, focos, luz e sombra pode levar também à percepção e ao entendimento de diferentes visões de mundo.

No presente trabalho, foram feitas leituras e interpretações de imagens veiculadas em cartazes de obras cinematográficas à luz das concepções da gramática visual de Kress e van Leeuwen ([1996] 2006), tendo sido essas leituras relacionadas à construção de significados sobre os filmes em questão. A partir da análise proposta, conclui-se que a mensagem visual de um cartaz de filme pode nos dizer muito sobre o conteúdo do filme porque oferece uma riqueza de significações. Os fundamentos da gramática visual de Kress e van Leeuwen ([1996] 2006) oferecem suporte teórico para a identificação e construção desses significados. Através da gramática visual, percebe-se como os elementos imagéticos no gênero cartaz de filme atuam semanticamente, contextualizando o filme. O texto imagético dialoga com a história narrada na sinopse, permitindo que o espectador construa a trama do filme.

Os significados construídos na análise das imagens utilizadas neste estudo representam somente uma parte de uma gama de significados possíveis. Afinal, os elementos presentes nas imagens ganham significado ao serem interpretados pelos diferentes leitores, cujas percepções dependem do contexto cultural em que estão inseridos e do conhecimento de mundo que trazem para a sua leitura. Por isso, precisamos preparar nossos alunos não só para ler o texto escrito, mas também para ler o texto imagético e perceber o valor do que foi explicitado ou aparentemente omitido, para inferir sentidos e significados, e para chegar a conclusões de forma que eles possam atuar conscientemente e criticamente na sociedade em que vivem. Sem dúvida, nesse cenário, o letramento visual pode fundamentar e transformar nossa prática pedagógica em ações que respondam às necessidades de nossos alunos no que concerne aos usos e práticas sociais de uma língua.

\section{REFERÊNCIAS}

Denzin, N. K. \& Lincoln, Y. S. (Orgs.). (2006). O planejamento da pesquisa qualitativa: teorias e abordagens. Porto Alegre: Artmed. 
Dionisio, A.G. (2005). "Gêneros multimodais e multiletramento". In: Brito, K. S. \& Gaydeczka, B.; Karwoski, A.M. (orgs). Gêneros textuais: reflexões e ensino. Palmas e União da Vitória, PR: Kayagangue.

Halliday, M.A.K. (1994). An Introduction to Functional Grammar. London: Edward Arnold.

Kern, R. (2009). Literacy and language teaching. Oxford: Oxford University.

Kleiman, A. B. (Org.) (1995). Os significados do letramento. Campinas: Mercado de Letras.

Kress, G. \& Leeuwen, T. V. ([1996] 2006). Reading Images: The Grammar of Visual Design. London: Routledge.

Marcuschi, L. A. (2001). "Letramento e oralidade no contexto das práticas sociais e eventos comunicativos”. In: Signorini, I. (Org.) Investigando a relação oral/escrito e as teorias do letramento. Campinas: Mercado de Letras.

Moles, A. A. (1978). O cartaz. São Paulo: Perspectiva apud Macedo, M.M. \& Gonçalves, S. P. (2008). Semiótica plástica na análise de cartazes de cinema - metaforização de estigmas sociais em cartazes de filmes brasileiros. Universidade Federal do Rio Grande do Sul. Rio Grande do Sul.

Nascimento, R.; Bezerra, F.A.S.; Heberle, E. M. (2011). Multiletramentos: iniciação à análise de imagens. Linguagem \& Ensino, Pelotas, v.14, n.2, p. 529-552, jul ./dez..

Neiva, JR, E. (2002). A imagem. São Paulo: Editora Ática.

Novellino, M. O. (2007). Fotografias em livro didático de inglês como língua estrangeira: análise de suas funções e significados. Dissertação de Mestrado, PUC-Rio.

Rojo, R. (2009). Letramentos Múltiplos, escola e inclusão social. São Paulo: Parábola, 2009.

Romanowski, J. P.; Martins, P. L. O. \& Junqueira, S. R. A. (Orgs.) (2004). Conhecimento local e conhecimento universal: diversidade, mídias e tecnologias na educação. Curitiba: Champagnat, v. 2, p. 245-253.

Silva, G. G. (2010). As imagens no ensino de língua estrangeira: um estudo de sala de aula por uma perspectiva multimodal. Dissertação de Mestrado, PUC-Rio.

Soares, M. B. (2001). Letramento: um tema em três gêneros. Belo Horizonte: Autêntica.

Street, B. (1984). Literacy in theory and practice. Cambridge: CUP. 
(2000). "Literacy events and literacy practices: theory and practice in the New Literacy Studies”. In: Martin-Jones, M \& Jones, K. (eds.). Multilingual literacies: reading and writing different worlds. Amsterdam, John Benjamins.

Teixeira, C. H. E. T. (2008a). A multimodalidade do gênero "livro didático de língua inglesa”: imagem, texto e função. Dissertação de Mestrado, PUC-Rio.

Teixeira, L. (2008b). “Achados e Perdidos: Análise semiótica de cartazes de cinema”. In: Lara, G. M. P.; Machado, I. L. \& Emediato, W. (Orgs.) Análises do discurso hoje. Rio de Janeiro: Nova Fronteira.

Unsworth, L. (2001). Teaching multiliteracies across the curriculum. Maidenhead, UK: Open University Press.

Viana, B. (2010). Teaser, imagens que provocam: a utilização do teaser de cartaz na saga Star Wars frente ao imaginário do público pós-moderno. Monografia de Graduação, Universidade Federal do Rio Grande do Sul apud Aita, L. M. (2011). Estratégias de promoção do cinema através dos cartazes: análise dos aspectos formais de peças dos gêneros aventura, comédia e drama. Monografia de Graduação, Universidade Federal do Rio Grande do Sul.

Weill, A. (2004). Graphics: A century of poster and advertising design. Londres: Thames \& Hudson.

\section{A AUTORA}

Célia Elisa Alves de Magalhães é especialista em língua inglesa pela UERJ e mestre em Estudos da Linguagem pela PUC-Rio. Atualmente, ministra aulas de inglês como língua estrangeira (EFL) na rede particular de ensino.

E-mail: elisa.celiamagalhaes@gmail.com 